\title{
Incretin-Based Antihyperglycemic Agents for the Management of Acute Ischemic Stroke in Patients with Diabetes Mellitus: A Review
}

\author{
Dimitrios Milonas · Triantafyllos Didangelos · Apostolos I. Hatzitolios • \\ Konstantinos Tziomalos
}

Received: January 9, 2019 / Published online: February 6, 2019

(C) The Author(s) 2019

\begin{abstract}
Diabetes mellitus (DM) is a major risk factor for ischemic stroke. Moreover, patients with DM suffer more severe strokes and have worse functional outcome following an acute stroke than patients without DM. In this context, data from animal studies and emerging evidence from clinical studies suggest that incretin-based antihyperglycemic agents might exert beneficial effects in patients with DM who suffer ischemic stroke. It appears that these agents exert neuroprotective actions that might both reduce infarct size and promote recovery. The present review summarizes the evidence on the potential role of incretin-based antihyperglycemic agents in the management of acute ischemic stroke.
\end{abstract}

Keywords: Diabetes mellitus; Incretin-based antihyperglycemic agents; Ischemic stroke; Outcome; Neuroprotection

Enhanced digital features To view enhanced digital features for this article go to https://doi.org/10.6084/ m9.figshare.7655039.

D. Milonas ( $₫)$ - T. Didangelos · A. I. Hatzitolios . K. Tziomalos

First Propedeutic Department of Internal Medicine, Medical School, Aristotle University of Thessaloniki, AHEPA Hospital, Thessaloniki, Greece e-mail: milonasdim.ver@gmail.com

\section{INTRODUCTION}

Ischemic stroke is a leading cause of death and long-term disability worldwide [1]. Type 2 diabetes mellitus (T2DM) is a major modifiable risk factor for ischemic stroke [2]. Indeed, patients with T2DM have a 2- to 6-fold higher risk of ischemic stroke and are also at higher risk of stroke recurrence [3-5]. Moreover, T2DM is associated with more severe stroke, resulting in higher rates of mortality and long-term dependency $[4,5]$.

During the acute phase of ischemic stroke, hyperglycemia is frequently observed and is associated with larger infarct and worse outcome [6]. Serum glucose levels persistently greater than $200 \mathrm{mg} / \mathrm{dl}$, especially during the first $24 \mathrm{~h}$ after stroke, independently predict expansion of the ischemic area and poor neurological outcomes, suggesting that management of hyperglycemia is an essential part of the acute management of patients with ischemic stroke [7]. Regarding in-patient glycemic control, the American Diabetes Association recommends a glucose target between 140 and $180 \mathrm{mg} / \mathrm{dl}$ for most patients in non-critical care units and subcutaneously administered insulin is considered the agent of choice [8]. Recent guidelines for the early management of acute stroke issued by the American Heart Association and the American Stroke Association make similar recommendations [9]. However, insulin therapy is associated with 
increased incidence of hypoglycemia and does not appear to reduce mortality in hospitalized patients [10-12]. Moreover, treatment with insulin does not appear to have any effect on the neurological deficit after an acute ischemic stroke [13, 14].

In this context, emerging evidence suggests that incretin-based antihyperglycemic agents, i.e., dipeptidyl peptidase (DPP)-4 and glucagonlike peptide 1 (GLP-1) receptor agonists, might exert beneficial effects in patients with T2DM who suffer ischemic stroke. It appears that these agents exert neuroprotective actions that might both reduce infarct size and promote recovery. The present review summarizes the evidence on the potential role of incretin-based antihyperglycemic agents in the management of acute ischemic stroke. We also briefly discuss the effects of these agents on the incidence of ischemic stroke in patients with T2DM. This article is based on previously conducted studies and does not contain any studies with human participants or animals performed by any of the authors.

\section{EFFECTS OF GLP-1 RECEPTOR AGONISTS ON ISCHEMIC STROKE RISK}

Several large, randomized, placebo-controlled trials evaluated the effects of GLP-1 receptor agonists on the incidence of ischemic stroke in patients with T2DM. In the Evaluation of Lixisenatide in Acute Coronary Syndrome (ELIXA) trial ( $n=6068$ patients with an acute coronary event within 180 days before screening), lixisenatide had no effect on the risk of nonfatal stroke during a median follow-up of 25 months [15]. In the Exenatide Study of Cardiovascular Event Lowering (EXSCEL) ( $n=14,752$ patients with or without established cardiovascular disease), extended-release exenatide also had no effect on the incidence of fatal or nonfatal stroke [16]. In the Liraglutide Effect and Action in Diabetes: Evaluation of Cardiovascular Outcome Results (LEADER) trial ( $n=9340$ patients $\geq 50$ years old with coronary heart disease, cerebrovascular disease, peripheral vascular disease, chronic kidney disease of stage 3 or greater, or chronic heart failure of New York Heart Association class II or III or $\geq 60$ years old with microalbuminuria or proteinuria, hypertension and left ventricular hypertrophy, left ventricular systolic or diastolic dysfunction, or ankle-brachial index $<0.9$ ), liraglutide had no effect on the incidence of fatal or nonfatal stroke or transient ischemic attack during a median follow-up of 3.8 years [17]. In the Harmony Outcomes $(n=9463$ patients with established coronary heart disease, cerebrovascular disease, or peripheral vascular disease), albiglutide had no effect on the risk of fatal or nonfatal stroke during a median follow-up of 1.6 years [18]. In contrast, in the Trial to Evaluate Cardiovascular and Other Long-term Outcomes with Semaglutide in Subjects with Type 2 Diabetes (SUSTAIN-6) ( $n=3297$ patients $\geq 50$ years old with coronary heart disease, cerebrovascular disease, peripheral vascular disease, chronic kidney disease of stage 3 or greater, or chronic heart failure of New York Heart Association class II or III or $\geq 60$ years old with microalbuminuria or proteinuria, hypertension and left ventricular hypertrophy, left ventricular systolic or diastolic dysfunction, or ankle-brachial index $<0.9$ ), treatment with semaglutide reduced the risk of nonfatal stroke by $39 \%$ during a median observation time of 2.1 years [19]. In a meta-analysis of ELIXA, LEADER, and SUSTAIN-6, GLP-1 receptor agonists had no effect on the risk of stroke [20].

\section{GLP-1 RECEPTOR AGONISTS AND ACUTE ISCHEMIC STROKE}

Activation of GLP-1 receptor by GLP-1 has been shown to be neurotrophic and to protect neurons against various insults [21]. Moreover, GLP-1 has been shown to cross the blood-brain barrier [22]. Liraglutide can also pass the blood-brain barrier but it is unclear whether other GLP-1 receptor agonists have the same property [23]. Accordingly, several preclinical studies evaluated the effects of GLP-1 receptor agonists in models of acute ischemic stroke. In these studies, a consistent reduction in infarct size was noted, along with an improvement in 
the functional outcome and a decrease in the neurological deficit [24-33]. These benefits have been observed with the use of both exenatide and liraglutide [24-33]. In the only study that compared these agents, they were similarly effective in improving brain perfusion and motor and cognitive deficits and in reducing brain edema, oxidative stress, inflammation, and apoptosis in diabetic mice with middle cerebral artery-induced stroke [34].

Notably, a neuroprotective effect was observed when GLP-1 receptor agonists were administered either prior to or after the ischemic insult [24-33]. However, in one study, exenatide was not beneficial when administered more than $3 \mathrm{~h}$ after ischemic stroke, suggesting that there is a limited time frame for this treatment [35]. In contrast, liraglutide improved the functional outcome even when administered 1 day after stroke [32]. In studies that compared different times of administration after stroke, GLP-1 receptor agonists appeared to be more beneficial when administered immediately after the ischemic insult [33, 35].

Very few studies compared the effects of GLP-1 receptor agonists with other antihyperglycemic agents in animal models of ischemic stroke. In an early study in diabetic and nondiabetic rats, treatment with liraglutide for 14 days prior to middle cerebral artery occlusion-induced stroke reduced the infarct volume and the neurological deficit more than vehicle and also attenuated oxidative stress, increased the expression of the anti-apoptotic protein $\mathrm{B}$ cell lymphoma-2 (Bcl-2), and reduced the expression of the pro-apoptotic protein Bax, resulting in decreased apoptosis of neuronal cells in the ischemic hemisphere [31]. These benefits were similar in diabetic and non-diabetic rats [31]. In contrast, stroke volume, neurological deficit, and severity of oxidative stress were similar in diabetic rats receiving either insulin or vehicle [31]. In a more recent study in diabetic rats, treatment with liraglutide for 7 days prior to middle cerebral artery occlusioninduced stroke reduced brain infarct volume whereas metformin had no effect despite similar reductions in blood glucose levels [30].

The beneficial effects of GLP-1 receptor agonists in animal models of ischemic stroke appear to be GLP-1 receptor-dependent, since knockout mice not expressing GLP-1 receptors show no benefit from GLP-1 receptor agonist treatment [24]. Moreover, GLP-1 receptor expression is reduced in ischemic brain regions and this decrease is reversed by GLP- 1 receptor agonists [25]. Several mechanisms appear to be implicated in the neuroprotective effects of GLP-1 receptor agonists. These agents attenuate microglial activation in the infracted area, which also appears to play a role in neuronal death [25]. GLP-1 receptor activation also inhibits cyclooxygenase- 2 through the modulation of the c-Jun NH2-terminal kinase (JNK) signaling pathway [26]. The latter induces an inflammatory response, which also contributes to neuronal death [26]. Exenatide was also shown to reduce the production of the proinflammatory cytokine tumor necrosis factor alpha [36]. Inhibition of neuronal apoptosis has also been shown to be associated with a decrease in infarct size during treatment with GLP-1 receptor agonists $[28,31]$. Activation of GLP-1 receptor also reduces oxidative stress following ischemic stroke and this appears to contribute to the reduction in infarct size $[27,34]$. On the other hand, the neuroprotective effects of GLP-1 receptor agonists appear to be glucose-lowering independent, since they are observed in non-diabetic animals and despite the absence of change in glucose levels [29, 30]. It also appears that GLP-1 receptor agonists do not affect cerebral blood flow [24].

\section{EFFECTS OF DPP-4 INHIBITORS ON ISCHEMIC STROKE RISK}

In several randomized, placebo-controlled trials, DPP-4 inhibitors had no effect on the risk of ischemic stroke in patients with T2DM [37-39]. In the Saxagliptin Assessment of Vascular Outcomes Recorded in Patients with Diabetes Mellitus (SAVOR)-Thrombolysis in Myocardial Infarction (TIMI) 53 trial $[n=16,492$ patients $\geq 40$ years old with coronary heart disease, cerebrovascular disease, or peripheral vascular disease, or $\geq 55$ years old (men) or $\geq 60$ years old (women) with dyslipidemia, hypertension, or active smoking], saxagliptin 
did not reduce the incidence of ischemic stroke during a median follow-up of 2.1 years [37]. In the Examination of Cardiovascular Outcomes with Alogliptin versus Standard of Care (EXAMINE) trial $(n=5380$ patients with an acute coronary syndrome within 15-90 days before randomization), alogliptin had no effect on the risk of nonfatal stroke during a median follow-up of 18 months [38]. In the Trial Evaluating Cardiovascular Outcomes with Sitagliptin (TECOS) $(n=14,671$ patients $\geq 50$ years old with coronary heart disease, cerebrovascular disease, or peripheral vascular disease), sitagliptin did not reduce the risk of fatal or nonfatal stroke during a median follow-up of 3 years [39]. In a meta-analysis of these three trials, DPP-4 inhibitors had no effect on the risk of stroke [20].

\section{DPP-4 INHIBITORS AND ACUTE ISCHEMIC STROKE}

Accumulating preclinical data suggest that DPP-4 inhibitors might exert neuroprotective actions in animal models of ischemic stroke. In diabetic mice, administration of linagliptin for 4 weeks prior to transient middle cerebral artery occlusion-induced stroke resulted in a noticeable, albeit not statistically significant, trend towards reduction of stroke volume [40]. In contrast, glimepiride had no effect on stroke volume [40]. Moreover, stereological counting of surviving neurons revealed significantly more (approximately 30\%) surviving neurons in linagliptin-treated mice than in glimepiride-treated animals [40]. Therefore, treatment with linagliptin prior to ischemic stroke appears to exert neuroprotective effects [40]. These effects appear to be unrelated to the glucose-lowering effect of linagliptin. Indeed, glucose levels decreased to a similar degree in linagliptin- and glimepiride-treated mice [40]. Moreover, in non-diabetic mice, both linagliptin and glimepiride induced a comparable and non-significant reduction in stroke volume and an increase in the number of surviving neurons [40]. In another study in non-diabetic mice, treatment with alogliptin for 3 weeks prior to ischemic stroke also reduced the volume of the infracted lesion and alleviated the severity of neurological deficit [41]. In contrast with GLP-1 receptor agonists, DPP-4 inhibitors do not appear to cross the blood-brain barrier [42]. It is possible that the neuroprotective effects of DPP-4 inhibitors are due to an increase in GLP-1 levels in the brain [40]. However, other investigators showed that the beneficial effects of DPP-4 inhibitors in animal models of ischemic stroke are independent of GLP-1 $[43,44]$. Another possible explanation is that DPP-4 has many other substrates except GLP1 , including peptides with potential neurotrophic or neuroprotective effects $[45,46]$. These include glucose-dependent insulinotropic polypeptide, pituitary adenylate cyclaseactivating polypeptide, and stromal cellderived factor 1a (SDF-1a) [47-49]. In preclinical models, these peptides were shown to promote synaptic plasticity, neurogenesis and neuronal differentiation, to inhibit apoptosis, and to reduce stroke size [47-49]. Indeed, linagliptin increased brain SDF-1a levels in mice subjected to stroke whereas inhibition of SDF-1a abolished the beneficial effects of linagliptin on stroke volume and motor function [44]. In addition, alogliptin was shown to increase the levels of brain-derived neurotrophic factor (BDNF), a potent brain neuroprotective cytokine, both in the cortex and in the whole forebrain [41]. Notably, acute administration of linagliptin at the time of stroke does not affect the outcome; therefore, it is questionable whether DPP-4 inhibitors have a role in the acute management of patients with ischemic stroke [43]. Despite these promising results of preclinical studies, there are very few data regarding the role of DPP-4 inhibitors in improving the outcome of patients with acute ischemic stroke. In a small study ( $n=123)$, we reported that patients who were hospitalized with acute ischemic stroke and were treated with DPP-4 inhibitors prior to stroke had a trend for less severe stroke at admission and also had better functional outcome and lower in-hospital mortality than patients treated with other antihyperglycemic agents [50]. 


\section{CONCLUSIONS}

Several preclinical studies consistently showed that GLP-1 receptor agonists reduce infarct volume and improve the functional outcome after ischemic stroke. These beneficial effects appear to be mediated by anti-inflammatory, antioxidant, and anti-apoptotic actions of these agents. On the other hand, glucose lowering does not appear to be implicated in the neuroprotective effect of GLP-1 receptor agonists, suggesting that they could have a role in the management of both diabetic and non-diabetic patients who suffer an ischemic stroke. More limited data suggest that DPP-4 inhibitors might also ameliorate neuronal damage following an ischemic stroke. However, it is unknown whether these results will translate into a clinical benefit in humans. Well-designed studies are needed to clarify the role of incretinbased antihyperglycemic agents in the management of acute ischemic stroke and to define the optimal dose and time of administration.

\section{ACKNOWLEDGEMENTS}

Funding. No funding or sponsorship was received for this study or publication of this article.

Authorship. All named authors meet the International Committee of Medical Journal Editors (ICMJE) criteria for authorship for this article, take responsibility for the integrity of the work as a whole, and have given their approval for this version to be published.

Disclosures. Dimitrios Milonas, Triantafyllos Didangelos and Apostolos I. Hatzitolios have nothing to declare. Konstantinos Tziomalos is a member of the journal's Editorial Board.

Compliance with Ethics Guidelines. This article is based on previously conducted studies and does not contain any studies with human participants or animals performed by any of the authors.
Open Access. This article is distributed under the terms of the Creative Commons Attribution-NonCommercial 4.0 International License (http://creativecommons.org/licenses/ by-nc/4.0/), which permits any noncommercial use, distribution, and reproduction in any medium, provided you give appropriate credit to the original author(s) and the source, provide a link to the Creative Commons license, and indicate if changes were made.

\section{REFERENCES}

1. GBD 2015 Mortality and Causes of Death Collaborators. Global, regional, and national life expectancy, all-cause mortality, and cause-specific mortality for 249 causes of death, 1980-2015: a systematic analysis for the Global Burden of Disease Study 2015. Lancet. 2016;388:1459-544.

2. Sarwar N, Gao P, Seshasai SR, et al. Diabetes mellitus, fasting blood glucose concentration, and risk of vascular disease: a collaborative meta-analysis of 102 prospective studies. Lancet. 2010;375:2215-22.

3. Sander D, Kearney MT. Reducing the risk of stroke in type 2 diabetes: pathophysiological and therapeutic perspectives. J Neurol. 2009;256:1603-19.

4. Tziomalos K, Spanou M, Bouziana SD, et al. Type 2 diabetes is associated with a worse functional outcome of ischemic stroke. World J Diabetes. 2014;5:939-44.

5. Reeves MJ, Vaidya RS, Fonarow GC, et al. Quality of care and outcomes in patients with diabetes hospitalized with ischemic stroke: findings from Get With the Guidelines-Stroke. Stroke. 2010;41:e409-17.

6. Kruyt ND, Biessels GJ, Devries JH, Roos YB. Hyperglycemia in acute ischemic stroke: pathophysiology and clinical management. Nat Rev Neurol. 2010;6:145-55.

7. Baird TA, Parsons MW, Phan T, et al. Persistent poststroke hyperglycemia is independently associated with infarct expansion and worse clinical outcome. Stroke. 2003;34:2208-14.

8. American Diabetes Association. Diabetes care in the hospital. Sec. 13. In: Standards of Medical Care in Diabetes-2016. Diabetes Care 2016;39)(Suppl. 1):S99-S104. 
9. Powers WJ, Rabinstein AA, Ackerson $\mathrm{T}$, et al. Guidelines for the early management of patients with acute ischemic stroke: a guideline for healthcare professionals from the American Heart Association/American Stroke Association. Stroke. 2018;2018(49):e46-110.

10. Turchin A, Matheny ME, Shubina M, Scanlon JV, Greenwood B, Pendergrass ML. Hypoglycemia and clinical outcomes in patients with diabetes hospitalized in the general ward. Diabetes Care. 2009;32:1153-7.

11. Gray CS, Hildreth AJ, Sandercock PA, et al. Glucosepotassium-insulin infusions in the management of post-stroke hyperglycaemia: the UK Glucose Insulin in Stroke Trial (GIST-UK). Lancet Neurol. 2007;6:397-406.

12. NICE-SUGAR Study Investigators, Finfer S, Liu B, et al. Hypoglycemia and risk of death in critically ill patients. N Engl J Med. 2012;367:1108-18.

13. McCormick M, Hadley D, McLean JR, Macfarlane JA, Condon B, Muir KW. Randomized, controlled trial of insulin for acute poststroke hyperglycemia. Ann Neurol. 2010;67:570-8.

14. Bellolio MF, Gilmore RM, Stead LG. Insulin for glycaemic control in acute ischaemic stroke. Cochrane Database Syst Rev. 2011;9:CD005346.

15. Pfeffer MA, Claggett B, Diaz R, et al. Lixisenatide in patients with type 2 diabetes and acute coronary syndrome. N Engl J Med. 2015;373:2247-57.

16. Holman RR, Bethel MA, Mentz RJ, et al. Effects of once-weekly exenatide on cardiovascular outcomes in type 2 diabetes. N Engl J Med. 2017;377:1228-39.

17. Marso SP, Daniels GH, Brown-Frandsen K, et al. Liraglutide and cardiovascular outcomes in type 2 diabetes. N Engl J Med. 2016;375:311-22.

18. Hernandez AF, Green JB, Janmohamed S, et al. Albiglutide and cardiovascular outcomes in patients with type 2 diabetes and cardiovascular disease (Harmony Outcomes): a double-blind, randomised placebo-controlled trial. Lancet. 2018;392:1519-29.

19. Marso SP, Bain SC, Consoli A, et al. Semaglutide and cardiovascular outcomes in patients with type 2 diabetes. N Engl J Med. 2016;375:1834-44.

20. Zhang Z, Chen X, Lu P, et al. Incretin-based agents in type 2 diabetic patients at cardiovascular risk: compare the effect of GLP-1 agonists and DPP-4 inhibitors on cardiovascular and pancreatic outcomes. Cardiovasc Diabetol. 2017;16:31.

21. Salcedo I, Tweedie D, Li Y, Greig NH. Neuroprotective and neurotrophic actions of glucagon-like peptide-1: an emerging opportunity to treat neurodegenerative and cerebrovascular disorders. $\mathrm{Br} \mathrm{J}$ Pharmacol. 2012;166:1586-99.

22. Kastin AJ, Akerstrom V, Pan W. Interactions of glucagon-like peptide-1 (GLP-1) with the bloodbrain barrier. J Mol Neurosci. 2002;18:7-14.

23. Secher A, Jelsing J, Baquero AF, et al. The arcuate nucleus mediates GLP-1 receptor agonist liraglutide-dependent weight loss. J Clin Invest. 2014;124:4473-88.

24. Li Y, Perry T, Kindy MS, et al. GLP-1 receptor stimulation preserves primary cortical and dopaminergic neurons in cellular and rodent models of stroke and Parkinsonism. Proc Natl Acad Sci USA. 2009;106:1285-90.

25. Lee $\mathrm{CH}$, Yan $\mathrm{B}$, Yoo $\mathrm{KY}$, et al. Ischemia-induced changes in glucagon-like peptide-1 receptor and neuroprotective effect of its agonist, exendin-4, in experimental transient cerebral ischemia. J Neurosci Res. 2011;89:1103-13.

26. Kim S, Jeong J, Jung HS, et al. Anti-inflammatory effect of glucagon like peptide-1 receptor agonist, exendin-4, through modulation of IB1/JIP1 expression and JNK signaling in stroke. Exp Neurobiol. 2017;26:227-39.

27. Briyal S, Gulati K, Gulati A. Repeated administration of exendin- 4 reduces focal cerebral ischemiainduced infarction in rats. Brain Res. 2012;1427:23-34.

28. Leker RR, Aharonowiz M, Greig NH, Ovadia H. The role of p53-induced apoptosis in cerebral ischemia: effects of the p53 inhibitor pifithrin alpha. Exp Neurol. 2004;187:478-86.

29. Darsalia V, Mansouri S, Ortsäter H, et al. Glucagonlike peptide-1 receptor activation reduces ischaemic brain damage following stroke in type 2 diabetic rats. Clin Sci (Lond). 2012;122:473-83.

30. Filchenko I, Simanenkova A, Chefu S, Kolpakova M, Vlasov T. Neuroprotective effect of glucagon-like peptide-1 receptor agonist is independent of glycaemia normalization in type two diabetic rats. Diab Vasc Dis Res. 2018;15:567-70.

31. Briyal S, Shah S, Gulati A. Neuroprotective and antiapoptotic effects of liraglutide in the rat brain following focal cerebral ischemia. Neuroscience. 2014;281:269-81.

32. Dong W, Miao Y, Chen A, et al. Delayed administration of the GLP-1 receptor agonist liraglutide improves metabolic and functional recovery after cerebral ischemia in rats. Neurosci Lett. 2017;641:1-7. 
33. Teramoto S, Miyamoto N, Yatomi K, et al. Exendin4 , a glucagon-like peptide-1 receptor agonist, provides neuroprotection in mice transient focal cerebral ischemia. J Cereb Blood Flow Metab. 2011;31:1696-705.

34. Li PC, Liu LF, Jou MJ, Wang HK. The GLP-1 receptor agonists exendin- 4 and liraglutide alleviate oxidative stress and cognitive and micturition deficits induced by middle cerebral artery occlusion in diabetic mice. BMC Neurosci. 2016;17:37.

35. Darsalia V, Hua $S$, Larsson $M$, et al. Exendin-4 reduces ischemic brain injury in normal and aged type 2 diabetic mice and promotes microglial M2 polarization. PLoS One. 2014;9:e103114.

36. Kuroki T, Tanaka R, Shimada Y, et al. Exendin-4 inhibits matrix metalloproteinase-9 activation and reduces infarct growth after focal cerebral ischemia in hyperglycemic mice. Stroke. 2016;47:1328-35.

37. Scirica BM, Bhatt DL, Braunwald E, et al. Saxagliptin and cardiovascular outcomes in patients with type 2 diabetes mellitus. $\mathrm{N}$ Engl J Med. 2013;369:1317-26.

38. White WB, Cannon CP, Heller SR, et al. Alogliptin after acute coronary syndrome in patients with type 2 diabetes. N Engl J Med. 2013;369:1327-35.

39. Green JB, Bethel MA, Armstrong PW, et al. Effect of sitagliptin on cardiovascular outcomes in type 2 diabetes. N Engl J Med. 2015;373:232-42.

40. Darsalia V, Ortsäter H, Olverling A, et al. The DPP-4 inhibitor linagliptin counteracts stroke in the normal and diabetic mouse brain: a comparison with glimepiride. Diabetes. 2013;62:1289-96.

41. Yang D, Nakajo Y, Iihara K, Kataoka H, Yanamoto H. Alogliptin, a dipeptidylpeptidase- 4 inhibitor, for patients with diabetes mellitus type 2 , induces tolerance to focal cerebral ischemia in non-diabetic, normal mice. Brain Res. 2013;1517:104-13.

42. Fuchs H, Binder R, Greischel A. Tissue distribution of the novel DPP-4 inhibitor BI 1356 is dominated by saturable binding to its target in rats. Biopharm Drug Dispos. 2009;30:229-40.
43. Darsalia V, Larsson M, Lietzau G, et al. Gliptinmediated neuroprotection against stroke requires chronic pretreatment and is independent of glucagon-like peptide-1 receptor. Diabetes Obes Metab. 2016;18:537-41.

44. Chiazza F, Tammen H, Pintana H, et al. The effect of DPP-4 inhibition to improve functional outcome after stroke is mediated by the SDF-1 $\alpha /$ CXCR4 pathway. Cardiovasc Diabetol. 2018;17:60.

45. Ahrén B, Hughes TE. Inhibition of dipeptidyl peptidase- 4 augments insulin secretion in response to exogenously administered glucagon-like peptide-1, glucose-dependent insulinotropic polypeptide, pituitary adenylate cyclase-activating polypeptide, and gastrin-releasing peptide in mice. Endocrinology. 2005;146:2055-9.

46. Mentlein R. Dipeptidyl-peptidase IV (CD26)-role in the inactivation of regulatory peptides. Regul Pept. 1999;85:9-24.

47. Figueiredo CP, Pamplona FA, Mazzuco TL, Aguiar AS, Walz R, Prediger RD. Role of the glucose-dependent insulinotropic polypeptide and its receptor in the central nervous system: therapeutic potential in neurological diseases. Behav Pharmacol. 2010;21:394-408.

48. Reglodi D, Somogyvari-Vigh A, Vigh S, Kozicz T, Arimura A. Delayed systemic administration of PACAP38 is neuroprotective in transient middle cerebral artery occlusion in the rat. Stroke. 2000;31:1411-7.

49. Yoo J, Seo JJ, Eom JH, Hwang DY. Effects of stromal cell-derived factor $1 \alpha$ delivered at different phases of transient focal ischemia in rats. Neuroscience. 2012;209:171-86.

50. Tziomalos K, Bouziana SD, Spanou M, et al. Prior treatment with dipeptidyl peptidase 4 inhibitors is associated with better functional outcome and lower in-hospital mortality in patients with type 2 diabetes mellitus admitted with acute ischaemic stroke. Diab Vasc Dis Res. 2015;12:463-6. 